\title{
(1) cartent \\ () \\ OPEN ACCESS \\ Successful sparing approach between the ascending aorta and the main pulmonary artery to the giant coronary aneurysm of the left main coronary artery
}

\author{
Ken Nakamura, Kouan Orii, Takayuki Abe, Hirofumi Haida
}

Cardiovascular Surgery, Saitama Cardiovascular and Respiratory Center, Kumagaya, Saitama, Japan

\section{Correspondence to} Dr Ken Nakamura; cardiacsurgken@ybb.ne.jp

Accepted 5 April 2020

\section{SUMMARY}

Coronary aneurysm located just above the left main coronary artery (LMT) is rare and difficult to treat. How the aneurysm is accessed is very important as it determines the result of the surgery. A 70-year-old man with a large coronary aneurysm (40 $\mathrm{mm}$ in diameter) in the LMT underwent surgery to prevent its rupture; however, there was severe adhesion. Initially, dissection of the ascending aorta or the pulmonary artery seemed necessary to access the aneurysm; however, the process was possible with limited dissection between the ascending aorta and the pulmonary artery, and we succeeded in firmly closing the LMT site of entry.

\section{BACKGROUND}

Recently, cases of giant coronary artery aneurysm (CAA) of coronary lesions have presented good operative results ${ }^{1-3}$; however, aneurysms that occur in areas other than the frontal and inferior areas and the lateral side are more difficult to treat. Only a few studies have reported giant CAA in the left main coronary artery (LMT). ${ }^{12}$ Here we describe a case of a giant saccular CAA located just above the LMT on the left side of the aorta and the posterior side of the main pulmonary artery.

\section{CASE PRESENTATION}

A 70-year-old man who previously had not undergone catheter examination or treatment presented with progression of chest oppression. He had no history of Kawasaki disease during childhood and other aneurysms. Cardiac catheterisation revealed double-vessel disease in the left descending artery (LAD) and right coronary artery (RCA), with a giant saccular coronary aneurysm of the LMT. Coronary artery CT (CACT) demonstrated a giant saccular CAA with a diameter of $40 \mathrm{~mm}$ on the posterior side of the main pulmonary artery. Blood flow was additionally noted from the RCA and the left circumflex artery into the aneurysm. According to the cardiovascular team's assessment, the LMT site of entry of the aneurysm was too large to be treated by covered stenting and the margin was too short to touch up covered stenting at the LMT. There was also the problem of treating the feeding arteries. Therefore, surgery was recommended.

The patient underwent surgery to prevent rupture and angina (figure 1). Cardiopulmonary bypass $(\mathrm{CPB})$ was established via cannulations of the ascending artery and both the vena cava. On the anterior surface of the pulmonary artery, meandering vessels that seemed to flow into the aneurysm were ligated. Coronary artery bypass was performed at the RCA and LAD with saphenous veins. Then, peeling of the adhesion off the surrounding tissue of the CAA was attempted; however, the pulmonary and ascending arteries were so severely adhered. As a result, the aneurysm was exposed just enough to access between the ascending aorta and the main pulmonary artery. Following aortic cross-clamping and cardiac arrest, the wall of the aneurysm was dissected at the right side of the main pulmonary artery. A large amount of thrombus filled the aneurysm. After removing the thrombus, the LMT site of entry of the aneurysm was examined by administering antegrade cardioplegia. The site of entry was of pinhole size, and therefore we were able to close it directly with 5-0 and 4-0 Prolene sutures with felt strips. The lumen of the aneurysm was filled with a haemostatic agent (factor XIII with fibrinogen). Furthermore, the aneurysm wall was closed by double sutures using 4-0 Prolene. No particular complication was observed in weaning from the CPB (figure 2).

A postoperative CACT confirmed the disappearance of the CAA and its drainage artery (figure 3).

\section{DIFFERENTIAL DIAGNOSIS}

Clinical observations during surgery strongly suggested pseudoaneurysm; however, due to limited dissection, we could not obtain much of the aneurysmal wall to diagnose the condition macroscopically.

\section{TREATMENT}

The patient underwent surgery.

\section{OUTCOME AND FOLLOW-UP}

A postoperative CACT confirmed the disappearance of the CAA and its drainage artery (figure 3 ). The patient was discharged on postoperative day 16 and was followed up until September 2019.

\section{DISCUSSION}

CAA located in the LMT has been recorded in only 22 of $22000(0.1 \%)$ catheterisations according to Topaz et al. ${ }^{4}$ This condition has multiple aetiologies, including atherosclerosis, Kawasaki disease, trauma, polyarteritis nodosa, systemic lupus 


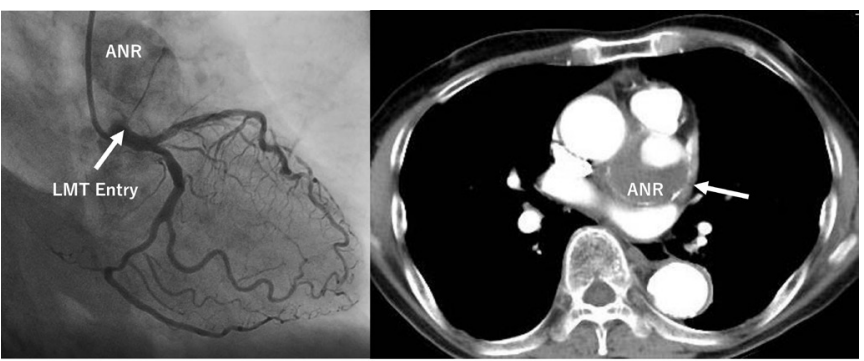

Figure 1 Cardiac catheterisation. (A) Cardiac catheterisation revealed jet blood flow $10 \mathrm{~mm}$ away from the left main coronary orifice. (B) Coronary artery CT showing a giant saccular coronary aneurysm with a diameter of $40 \mathrm{~mm}$ on the posterior side of the pulmonary artery. LMT, left main coronary artery.

erythematosus, syphilis and other idiopathic causes. ${ }^{5}$ In general, CAA is defined as ectasia of the coronary artery lumen up to 1.5 times the normal diameter size. Among these aneurysms, the giant type is characterised by a diameter of $>4 \mathrm{~cm} .{ }^{6}$ The present case involved a giant type of aneurysm with a diameter of $40 \mathrm{~mm}$. However, the prevalence of giant aneurysm is only $0.02 \%-0.2 \%$ and is much rarer than smaller aneurysms. ${ }^{7}$

The most important problem to consider is how to access an aneurysm originating near the site of the LMT orifice and at the posterior side of the main pulmonary artery. Indeed, between the aorta and the pulmonary artery (Ao-PA), there was severe adhesion which allowed only limited dissection. Initially, dissection of the ascending aorta seemed necessary in order to observe and treat the aneurysm; however, it was possible to access the aneurysm from the top, at the site of the Ao-PA, with only limited dissection allowed. The cardiac arrest enabled easy observation of the visual field, and the LMT site of entry was easily identified from the top of the aneurysm by administering an antegrade cardioplegic solution. The large cavity filled with blood clot was also good for operative observations; however, a large amount of blood clot is considered a risk factor for the occurrence of angina or myocardial infarction. It was essential to rid of all blood clot and tightly close the LMT site of entry and to identify the drainage arteries to prevent recurrence. The pinhole size of the LMT orifice allowed us to close it directly and firmly by sutures using felt strips. We also paid attention not to leave residual shunt and create a stenosis at the LMT by

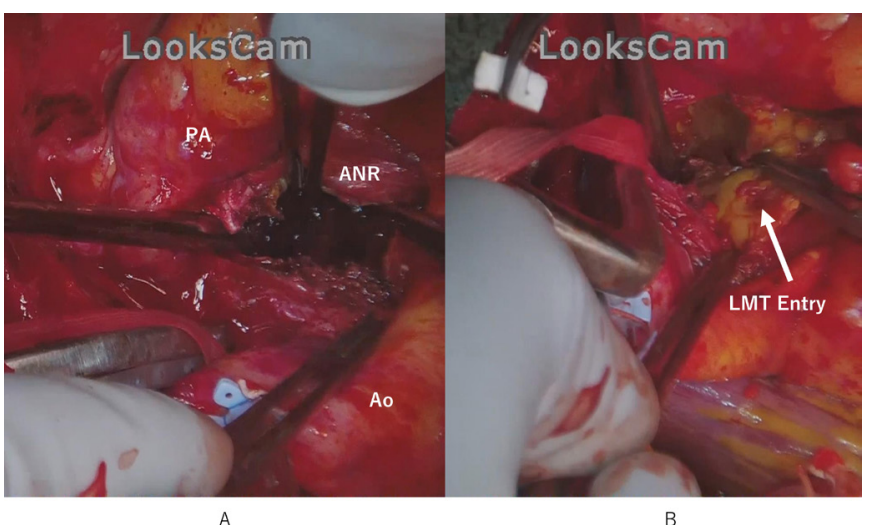

Figure 2 The surgery. (A) A large amount of thrombus filled the aneurysm. (B) The entry point (arrow) was closed by $5-0$ and $4-0$ Prolene sutures with felt strips. Ao, aorta; LMT, left main coronary artery; $\mathrm{PA}$, pulmonary artery.

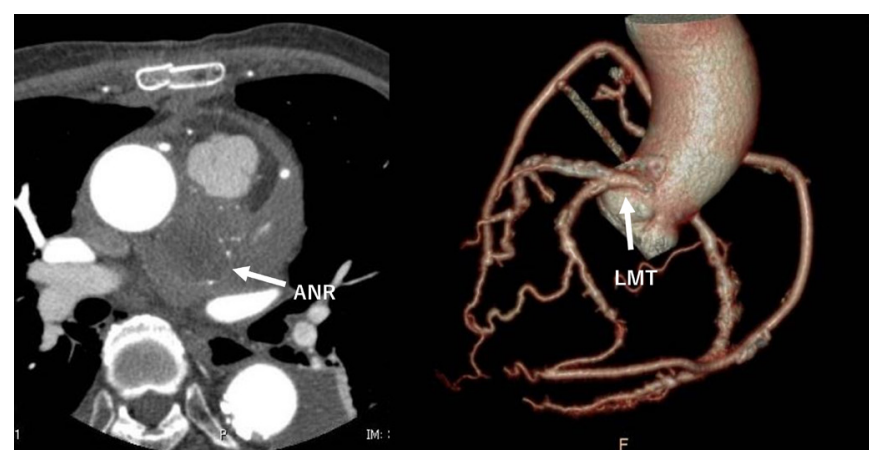

Figure 3 Coronary artery CT after surgery confirmed the disappearance of the coronary aneurysm and its drainage artery. LMT, left main coronary artery.

administering an antegrade cardioplegic solution. However, anxiety remained until the result of the surgery was confirmed by CACT. The surgery seemed very simple with direct access and closure of the LMT site of entry; some reports presented an aortotomy approach for sinus node artery aneurysm arising from the LMT or access from the aneurysmal sac drainage into the right atrium. ${ }^{89}$ It was also essential to identify the drainage arteries in case of recurrence; however, it was difficult to identify all the collateral vessels. Therefore, the cavity of the aneurysm was closed using a haemostatic agent (factor XIII with fibrinogen), and the meandering vessels identified on the frontal area of the pulmonary artery were closed as much as possible to prevent future dilatation. In the literature, there is no reported consensus on the treatment of giant coronary aneurysms. Our cardiac team first considered the use of covered stents, but we were anxious if it will successfully exclude the aneurysm. Kim et $a l^{10}$ succeeded in treating a giant coronary aneurysm with percutaneous Viabahn covered stent insertion. Cotter et al ${ }^{11}$ also reported successfully excluding the aneurysm with a long drugeluting stent. However, both of these were limited to the RCA.

Clinical observations during surgery strongly suggested pseudoaneurysm; however, due to limited dissection, we could not obtain much of the aneurysmal wall to diagnose this condition macroscopically. Wang et $a l^{12}$ reported the pathogenesis of coronary pseudoaneurysm is not well understood. One of the reasons might be due to incomplete rupture of the coronary artery induced by atherosclerotic, degenerative, congenital, inflammatory, traumatic causes and so on.

Only few studies have reported an aneurysm originating from the LMT after catheter treatment or surgery. ${ }^{13}$ However, in the present case, the patient had not undergone previous catheter examination or treatment. History and clinical observations during the surgery strongly suggested pseudoaneurysm due to atherosclerosis. We could not find other reports of pseudo-giant LMT coronary aneurysm. This might be the first report of an aneurysm that was successfully treated by direct limited entry through the aneurysm wall in the Ao-PA without dissecting the ascending aorta or the main pulmonary artery.

\section{Learning points}

- Left main coronary artery aneurysm is difficult to access due to the peripheral structures.

- How the aneurysm is accessed is very important as it determines the result of the surgery.

- Idiopathic coronary aneurysm is an extremely rare case. 
Contributors $\mathrm{KN}$ and $\mathrm{KO}$ were involved in direct patient care. $\mathrm{KN}$, TA and $\mathrm{HH}$ planned, collected the data and prepared the manuscript. KN supervised the preparation of the manuscript.

Funding The authors have not declared a specific grant for this research from any funding agency in the public, commercial or not-for-profit sectors.

Competing interests None declared.

Patient consent for publication Obtained.

Provenance and peer review Not commissioned; externally peer reviewed.

Open access This is an open access article distributed in accordance with the Creative Commons Attribution Non Commercial (CC BY-NC 4.0) license, which permits others to distribute, remix, adapt, build upon this work non-commercially, and license their derivative works on different terms, provided the original work is properly cited and the use is non-commercial. See: http://creativecommons.org/ licenses/by-nc/4.0/.

\section{REFERENCES}

1 Luckraz H, Parums DV, Dunning J. Reverse saphenous interposition vein graft repair of a giant atherosclerotic aneurysm of the left anterior descending coronary artery. J Thorac Cardiovasc Surg 2002;123:817-20.

2 Libertini R, Wallbridge $D$, Jones $H R$, et al. Giant circumflex artery aneurysm with a coronary sinus fistula. Ann Thorac Surg 2018;106:e223-5.
3 Mawatari T, Koshino T, Morishita K, et al. Successful surgical treatment of giant coronary artery aneurysm with fistula. Ann Thorac Surg 2000;70:1394-7.

4 Topaz O, Disciascio G, Cowley MJ, et al. Angiographic features of left main coronary artery aneurysms. Am J Cardiol 1991;67:1139-42.

5 Alioglu E, Turk UO, Engin C, et al. Left main coronary artery aneurysm in young patient with acute myocardial infarction. J Cardiovasc Med 2009; 10:494-6.

6 Zhu Z, Wang Y, Xu R, et al. Giant aneurysm of the left main coronary artery with fistulous communication to the right atrium. J Cardiothorac Surg 2015;10:117.

7 Crawley PD, Mahlow WJ, Huntsinger DR, et al. Giant coronary artery aneurysms: review and update. Tex Heart Inst J 2014;41:603-8.

8 Huang J, Zeng K, Yang Y, et al. Sinus node artery aneurysm arising from the left main coronary artery with a fistula into the right atrium. J Card Surg 2019;34:37-40.

9 Jacobsen $\mathrm{K}$, Khouzam N. Left main coronary artery aneurysm with a fistula draining into the right atrium. J Card Surg 2018;33:803-5.

10 Kim T-H, Marfatia R, Lee J, et al. Giant coronary aneurysm management with Viabahn covered stent. Cardiovasc Revasc Med 2017;18:56-9.

11 Cotter R, Krantz M, Hogan S, et al. Exclusion of a giant coronary artery aneurysm with covered stents using a long drug-eluting stent scaffold. Clin Med Insights Case Rep 2019;12:117954761982868-3.

12 Wang L, Wang J, Cheng TO, et al. Giant left coronary artery aneurysms: review of the literature and report of a rare case diagnosed by transthoracic echocardiography. Int J Cardiol 2015;189:267-71.

13 Hagau AMT, Dudea SM, Hagau R, et al. Large coronary pseudoaneurysm with pulmonary artery fistula, six months after left main trunk stenting with paclitaxeleluting stent. Med UItrason 2013;15:59-62.

Copyright 2020 BMJ Publishing Group. All rights reserved. For permission to reuse any of this content visit

https://www.bmj.com/company/products-services/rights-and-licensing/permissions/

BMJ Case Report Fellows may re-use this article for personal use and teaching without any further permission.

Become a Fellow of BMJ Case Reports today and you can:

- Submit as many cases as you like

- Enjoy fast sympathetic peer review and rapid publication of accepted articles

- Access all the published articles

Re-use any of the published material for personal use and teaching without further permission

\section{Customer Service}

If you have any further queries about your subscription, please contact our customer services team on +44 (0) 2071111105 or via email at support@bmj.com.

Visit casereports.bmj.com for more articles like this and to become a Fellow 